\title{
A STUDY OF THE "NORMAL" HIP IN CHILDREN WITH UNILATERAL PERTHES' DISEASE
}

\author{
M. H. M. HARRISON, M. E. BLAKEMORE
}

From The Royal Orthopaedic Hospital, Birmingham

\begin{abstract}
The radiographs of 153 children suffering from Perthes' disease of one hip were studied to examine the bony outline of the femoral capital epiphysis in the unaffected hip. In 48.4 per cent of patients irregularity of the surface, flattening or dimpling; were noted; in the majority of instances (37.2 per cent) these changes were present in the initial anteroposterior radiograph. By contrast, these changes were present in only 10.4 per cent of a control series of 153 children in whom intravenous urography was being performed, these children being matched for age and sex with the children with Perthes' disease. A second unmatched control series of 49 children whose pelves were being radiographed after injury showed a 6.1 per cent incidence of contour irregularities in 98 femoral capital epiphyses. In the patients with Perthes' disease and in the control series obtained at urography the incidence of changes was inversely related to age. The possible cause and significance of contour irregularities in normal children and in those with Perthes' disease is discussed.
\end{abstract}

From the first published descriptions it has been recognised that children with Perthes' disease may have both hips affected although unilateral disease is by far the most common. Reports of the incidence of bilateral disease have varied, giving figures between 9 and 17 per cent (Table I). At the Perthes' Clinic started in 1960 at the Royal Orthopaedic Hospital, Birmingham, where a large number of radiographs of affected children have

Table I. Incidence of bilateral Perthes' disease

\begin{tabular}{|lc|c|c|}
\hline \multicolumn{1}{|c|}{ Authors } & & $\begin{array}{c}\text { Total number } \\
\text { of patients }\end{array}$ & $\begin{array}{c}\text { Bilateral } \\
\text { disease } \\
\text { (per cent })\end{array}$ \\
\hline Sundt & $(1949)$ & 255 & 14.0 \\
Goff & $(1954)$ & 103 & 17.0 \\
Mose & $(1964)$ & 255 & 10.9 \\
Katz & $(1965)$ & 208 & 9.0 \\
Kemp and Boldero & $(1966)$ & 220 & 10.0 \\
Catterall & $(1973)$ & 389 & 16.4 \\
Wynne-Davies and Gormley & $(1978)$ & 310 & 11.3 \\
\hline
\end{tabular}

been studied, the impression has gradually strengthened that the femoral capital epiphysis shows radiographic changes not only in the frankly affected hip, but commonly on the contralateral side. The present study was undertaken to determine the incidence and significance of some of these changes.
At the conclusion of this investigation our attention was drawn to three papers of which we had previously been unaware which detail similar changes to those we now report. Katz (1965) found that 33 of 190 children with unilateral Perthes' disease had asymptomatic changes in contour of the femoral head of the contralateral hip. No normal children were studied as controls and he postulated this could be an "abortive" form of Perthes' disease. Emr and Komprda (1968) carried out a study which was essentially similar to the one described in this paper; their material included 103 children with Perthes' disease, 80 children with "observation hip" and 188 healthy children whose hips were being radiographed for the purpose of investigating the variations of normal development. The presentation of their material does not allow an absolute comparison between their work and ours but their findings appear to be confirmatory. Chivabongs (1972) considered that changes could be found in the "normal" hip of patients with unilateral Perthes' disease to a degree which suggested that the disease is bilateral to a far greater extent than had previously been recognised. We believe that the radiological changes which we now report have been identified by these authors.

\section{MATERIAL AND METHODS}

The radiographs and case notes of all children registered at the Perthes' Clinic of the Royal Orthopaedic Hospital, Birmingham, between January 1971 and December 1976 were reviewed with particular regard to the radiographic appearances of the femoral capital epiphysis in the hip opposite to the one affected by Perthes' 
disease. There were 222 new patients registered during this period, 69 of whom were excluded from futher study for the following reasons.

Twenty-three patients had bilateral Perthes' disease. Seven of these presented with unilateral disease but the contralateral hip became affected during their treatment; a further reference to five of these patients is made in the discussion.

Twenty-three patients showed radiographic changes which, throughout the period of observation, were never typical of Perthes' disease. In some children there was merely a contour irregularity of the capital epiphysis without any metaphysial changes. Sequential radiographs of these patients did not show the progressive changes typical of Perthes' disease, but instead there was a gradual return to normality in those followed up for a sufficiently long period. These patients probably represent one part of the spectrum of Perthes' disease with very modest involvement of the epiphysis in a younger age group, the average age of these 23 patients being 4.7 years. Such cases were described by Pedersen (1960) and Meyer (1964) and named "dysplasia epiphysealis capitis femoris". This group also included some whose radiographs showed minor changes of the ossific nucleus, similar to those described by Katz $(1965,1968)$ as "minimal" or "abortive" Perthes' disease.

Twenty-three patients were excluded from further consideration because for 10 the notes or radiographs were inadequate and $13 \mathrm{had}$ a local or generalised condition which may have contributed to abnormalities in the contralateral hip (Table II).

Table II. Reasons for exclusion of 23 patients

\begin{tabular}{|lc|}
\hline Inadequate or unavailability of notes or radiographs & 10 \\
Treated dislocated or dislocatable hip & 4 \\
Sickle-cell trait & 1 \\
Gaucher's disease & 1 \\
Haemophilia & 1 \\
Spondylo-epiphysial dysplasia & 1 \\
Thalassaemia & 1 \\
Chondrodysostosis & 1 \\
Primary hyperparathyroidism & 1 \\
Osteomyelitis of the femoral neck & 1 \\
Rubinstein-Taybi syndrome & 1 \\
\hline
\end{tabular}

The majority of the remaining 153 patients were diagnosed as suffering from Perthes' disease during the phase in which the radiographs showed increased density or early fragmentation. There were seven patients first seen in the late fragmentation or reconstitution phases.

Changes in the contralateral hip. The radiographs of the 153 patients with unilateral Perthes' disease were examined with particular reference to the presence or absence of contour irregularities of the capital epiphysis in the hip opposite to the one with Perthes' disease. All of these children were Caucasians except one child of Indian origin.

The radiographic changes noted were those of alteration of the smooth, curved contour of the femoral capital epiphysis producing either an abrupt flattening over a variable extent of the outline, or single or multiple "dimples". Surface flattening was much commoner than a single dimple and multiple dimpling was rare and occurred only in the younger patients. Examples of these contour irregularities are given in Figures 1 to 6; it will be noted that the radiographic lesions were found either on the summit or the front half of the capital epiphysis. The irregularities were usually seen in both the anteroposterior and "frog" lateral radiographs although they were sometimes visible in only one of these projections. These were considered to be present when they could be identified in two radiographic projections taken on a single date, or when they could be consistently identified in one radiographic projection on two or more consecutive dates, usually separated by three months. Appearances due to superimposition of the irregular posterior edge of the acetabulum were carefully excluded as was the medial indentation which marks the insertion of the ligamentum teres (Fig. 3). The contour irregularities persisted for a varying length of time; whereas they could be effaced within six months, uncommonly they persisted for more than 42 months.

Control groups. To determine the significance of these epiphysial contour irregularities in the contralateral hip of children with unilateral Perthes' disease, two control series were studied.

Series 1 consisted of 153 radiographs of hip joints (anteroposterior projections), obtained incidentally during intravenous urography of children matched for age and sex with 153 children who had unilateral Perthes' disease. Six of these children were of Indian origin, the remainder were Caucasians. Urography was undertaken for the investigation of recurrent problems of the urinary tract; children with spina bifida were excluded. Fifty-five per cent of the urograms were normal, 29 per cent showed evidence of obstructive or reflux uropathy, 11 per cent showed a congenital abnormality and five per cent showed miscellaneous conditions. We appreciate that this control series was not a normal population but the following points must be considered. First, the nature of our study dictated that "normal" hip radiographs taken from children attending an orthopaedic clinic would have been entirely unsuitable as they would inevitably have been suspect of harbouring a "forme fruste" of a skeletal abnormality. Secondly, if a control series of children with suspected renal abnormalities produced any bias it would be likely to diminish rather than increase the significance of the changes found in the "normal" hips, since an abnormally high incidence of disorders of the genito-urinary tract has been found in association with Perthes' disease (Catterall, LloydRoberts and Wynne-Davies 1971). Since deliberate radiography of normal children would be unethical we sought confirmation of our findings in Series 1 with the more evidently normal children of Series 2. Series 2 consisted of 49 children, 32 boys and 17 girls, whose pelves had been radiographed in the anteroposterior projection because of injury; 23 children had sustained a fracture and none had a history of spontaneous pain of the hip, thigh or knee. This series was matched neither for age nor sex with the 153 children with Perthes' disease.

The irregularities of contour found in some of the "normal" hips of the children with Perthes' disease were also found in a number of hips in each of the control series. The irregularities were of similar appearance but were usually smaller.

\section{RESULTS}

The radiographs of the contralateral, unaffected hip of the 153 children affected by unilateral Perthes' disease showed contour irregularities in the anteroposterior projection or in the lateral projection, or in both, in 74 cases, an incidence of $\mathbf{4 8 . 4}$ per cent. The incidence was inversely proportional to age (Table III).

In control Series 1 , only one hip of the two shown in each control radiograph was studied, that of the same side as the "contralateral hip" of the child with unilateral Perthes' disease. The number of matched control hips which showed contour irregularity was 16 (10.4 per cent) and again the incidence seemed rather higher in the younger age groups (see Table V). The age and sex distribution of the children with Perthes' disease and of the controls is shown in Table IV.

The contour irregularities found in the group affected by unilateral Perthes' disease were in some 


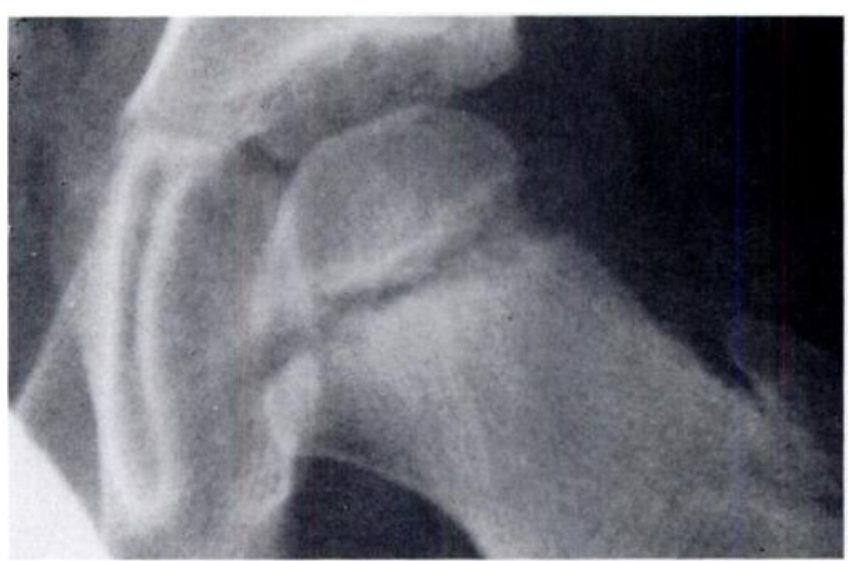

Fig. 1

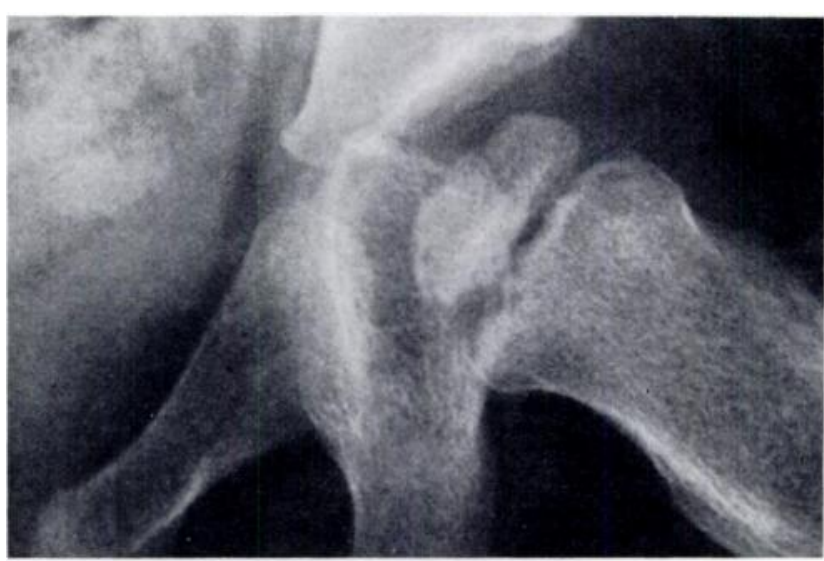

Fig. 2

Anteroposterior (Fig. 1) and "frog" lateral (Fig. 2) radiographs showing flattening of the dome of the femoral capital epiphysis.

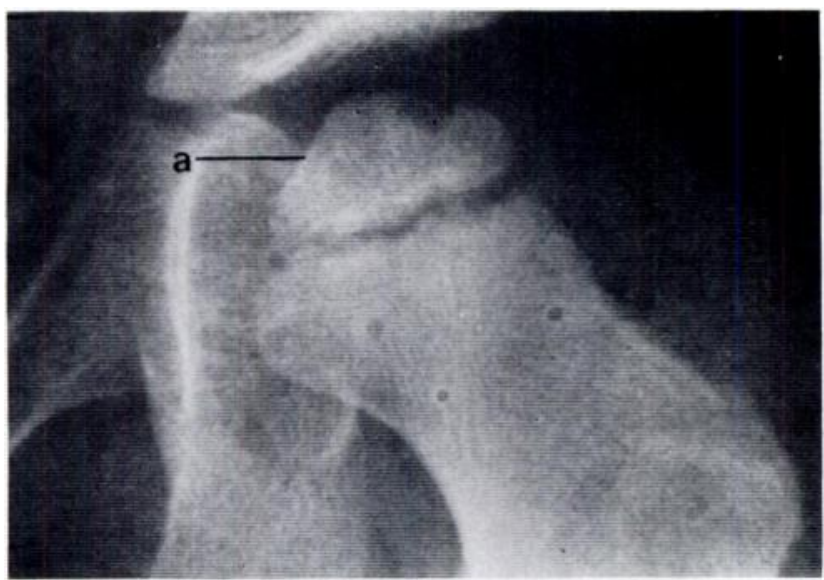

Fig. 3

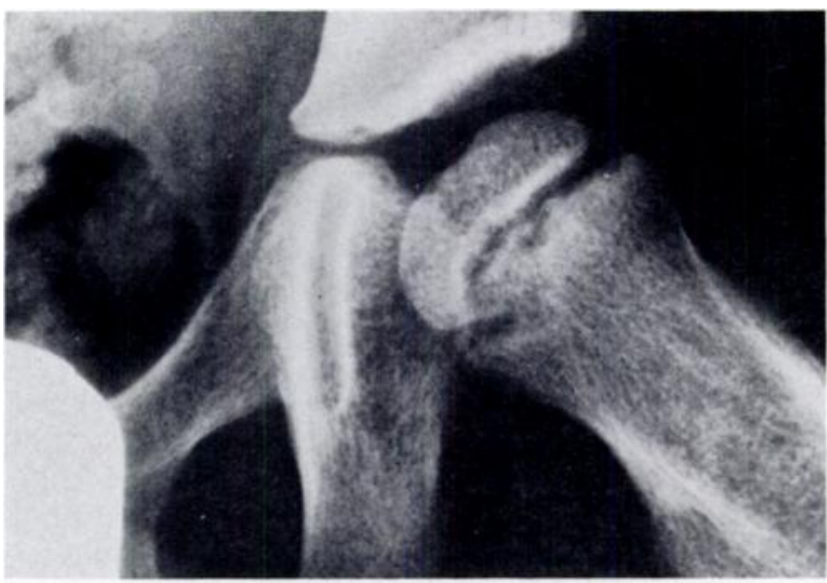

Fig. 4

Figure 3-The lateral side of the dome of the femoral capital epiphysis bears a "dimple" defect; $a$ marks the normal medial flattening of the epiphysis at the insertion of the ligamentum teres. Figure 4- "Frog" lateral radiograph showing a broad dimpling on the dome of the femoral capital epiphysis.

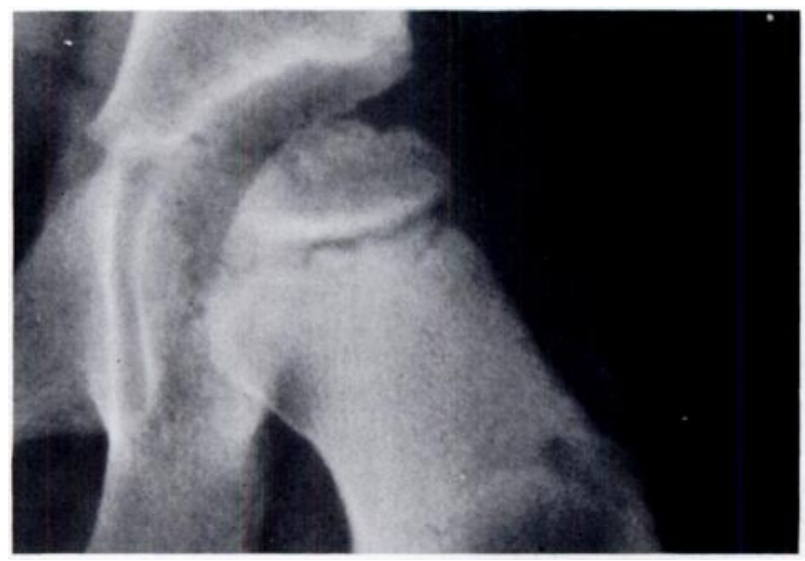

Fig. 5

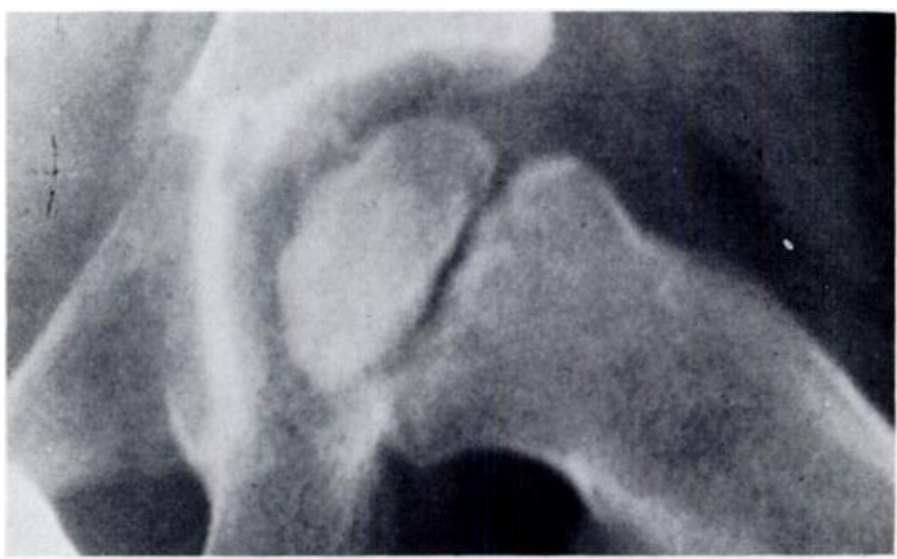

Fig. 6

Figure 5-Anteroposterior radiograph showing multiple dimpling of the summit of the femoral capital epiphysis. Figure 6-"Frog" lateral radiograph showing two broad dimples on the summit. 
Table III. The incidence of contour irregularities in the contralateral hip of children with unilateral Perthes' disease at various ages

\begin{tabular}{|c|c|c|c|}
\hline \multirow{2}{*}{$\begin{array}{c}\text { Age } \\
\text { (years) }\end{array}$} & \multirow{2}{*}{$\begin{array}{l}\text { Total number of } \\
\text { children with } \\
\text { Perthes' disease }\end{array}$} & \multicolumn{2}{|c|}{$\begin{array}{l}\text { Children with } \\
\text { contralateral irregularities }\end{array}$} \\
\hline & & Number & Per cent \\
\hline Total & 153 & 74 & 48.4 \\
\hline Under 7 & 100 & 67 & 67.0 \\
\hline Under 6 & 72 & 52 & 72.2 \\
\hline Under 5 & 45 & 36 & 80.0 \\
\hline Under 4 & 17 & 14 & 82.3 \\
\hline Under 3 & 2 & 2 & 100 \\
\hline
\end{tabular}

Table IV. Comparison of the incidence of contour irregularities in the contralateral hip of patients with Perthes' disease and that in controls

\begin{tabular}{|c|c|c|c|c|}
\hline & \multicolumn{2}{|c|}{ Perthes' series } & \multicolumn{2}{|c|}{ Controls (Series 1) } \\
\hline & $\begin{array}{l}\text { Contour } \\
\text { Present }\end{array}$ & $\begin{array}{l}\text { gularity } \\
\text { Absent }\end{array}$ & $\begin{array}{l}\text { Contour } \\
\text { Present }\end{array}$ & $\begin{array}{l}\text { egularity } \\
\text { Absent }\end{array}$ \\
\hline Number of children & 74 & 79 & 16 & 137 \\
\hline Average age (years) & 4.97 & 7.38 & 4.5 & 6.41 \\
\hline Male to female ratio & $3.6: 1$ & $3.9: 1$ & $3.0: 1$ & $3.9: 1$ \\
\hline
\end{tabular}

Comparative incidence $(74 / 16)$ is significant at $P<0.001$ using Student's paired $t$ test.

Table V. A comparison of the incidence of contour irregularities in the contralateral hip of patients with Perthes' disease and that of controls as judged on the anteroposterior radiograph taken at the child's first attendance at the clinic

\begin{tabular}{|l|c|c|c|c|c|}
\hline & \multirow{2}{*}{$\begin{array}{c}\text { Age } \\
\text { (years) }\end{array}$} & \multirow{2}{*}{$\begin{array}{c}\text { Number of } \\
\text { children }\end{array}$} & \multicolumn{2}{|c|}{ Perthes' series } & \multicolumn{2}{c|}{ Controls (Series 1) } \\
\cline { 3 - 6 } & Number & Per cent & Number & Per cent \\
\hline Total & 153 & 57 & 37.2 & 16 & 10.4 \\
Under 7 & 100 & 53 & 53.0 & 15 & 15.0 \\
Under 6 & 72 & 43 & 59.7 & 14 & 19.4 \\
Under 5 & 45 & 30 & 66.6 & 9 & 20.0 \\
Under 4 & 17 & 14 & 82.3 & 5 & 29.3 \\
Under 3 & 2 & 2 & 100 & 1 & 50.0 \\
\hline
\end{tabular}

cases seen only in the lateral projection and in some cases not on every occasion that the radiographic examination was carried out. Therefore, it was felt necessary to compare the 10.4 per cent incidence in control Series 1 with that of the children with Perthes' disease evident in the anteroposterior radiograph taken on the first attendance at the clinic. Of the total of 153 children with Perthes' disease, 57 showed contour irregularities on the first anteroposterior radiograph (37.2 per cent). The incidence in the different age groups was compared with that in the controls (Table V).

Control Series 2 provided anteroposterior radiographs of both hips of 49 patients: 6.1 per cent of these 98 femoral heads showed contour irregularities. Boys and girls were more or less equally affected in this series.

\section{DISCUSSION}

The aetiology of contour irregularities. Any explanation of the irregularities reported in this paper must explain their incidence both in the hips of normal children and in even greater numbers in the apparently unaffected hip of children with unilateral Perthes' disease. In both groups the changes are related to age, being most common in younger children. It is therefore possible that the irregularities are a temporary developmental feature in most or all children which is effaced as the child grows older. The higher incidence in children with Perthes' disease might be explained by the fact that these children have a marked tendency to skeletal immaturity (Harrison, Turner and Jacobs 1976) with a bony epiphysial development retarded months or years behind their calendar age. They might thus be expected to show a greater incidence of a developmental change to which young children are prone.

An alternative hypothesis would explain the sectoral flattenings of contour and the indentations of the subchondral bone as being the result of "high spots" of pressure loading. Somewhat similar appearances are well-recognised pressure phenomena in osteoarthritis of the hip (Harrison, Schajowicz and Trueta 1953) where excessive loading of bone is due essentially to derangement of normal anatomy with secondary loss of articular cartilage. What could be the cause of abnormal bone loading in both normal children and those with Perthes' disease? Knock knee in normal young children aged two or three years may provide a clue, for this deformity usually corrects spontaneously with growth and probably is an expression of the skeleton yielding in the face of functional demand. The human hip is known to transmit the very highest loads and the contour irregularities may be evidence of stress on the young capital epiphysis, more common in the younger age groups because functional demand is accelerating faster than structural development. The higher incidence in children with Perthes' disease could be a reflection of skeletal immaturity although that has not yet been shown to affect the hip; to date this has only been studied in the carpus and the knee. Another possible contributory cause of the higher incidence in children with Perthes' disease could be the relatively poor performance of the chondroblast or the osteoblast (or both) which has been revealed in our studies of growth in children affected by this disease (Burwell et al. 1978); 


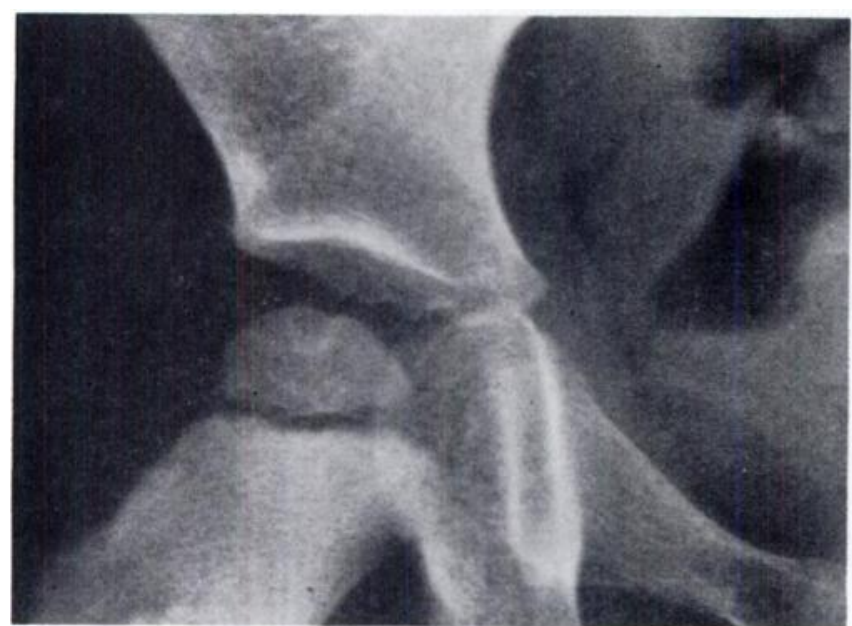

Fig. 7

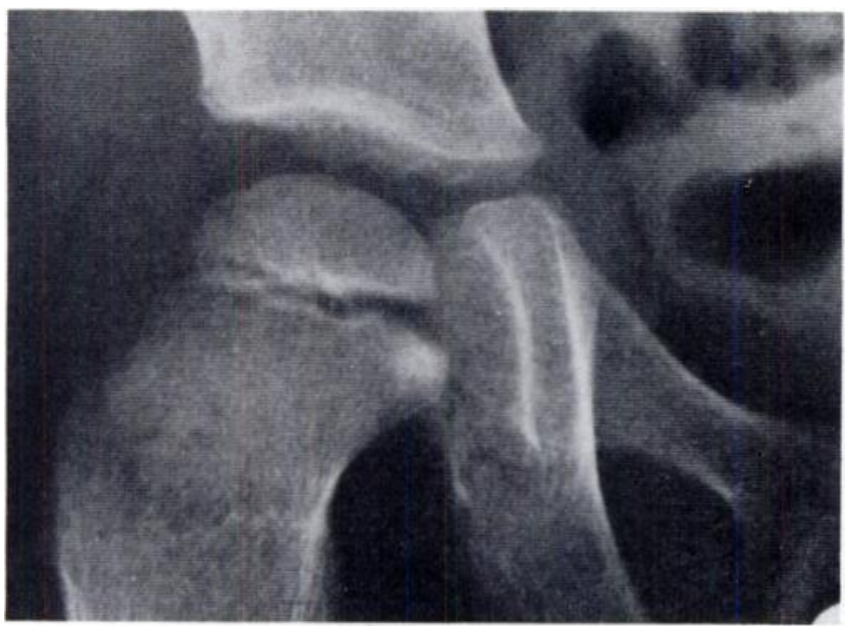

Fig. 9

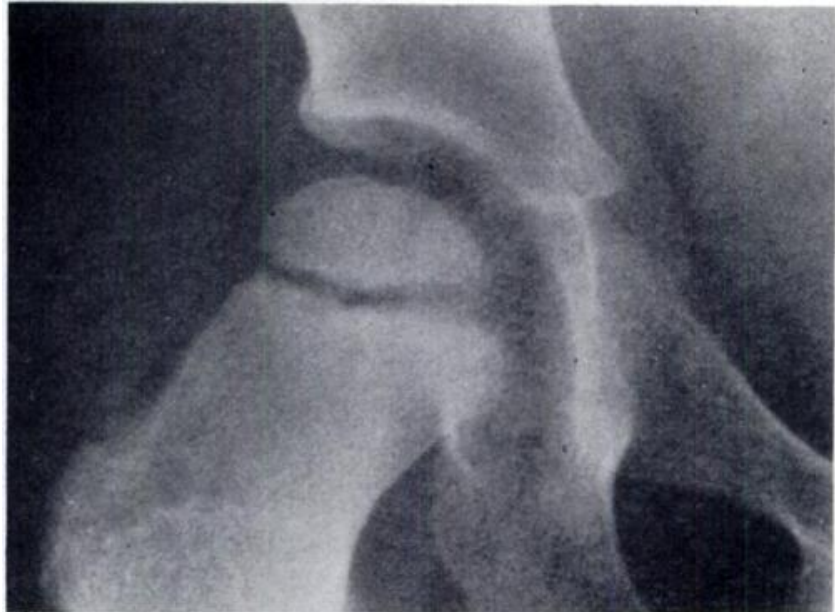

Fig. 8

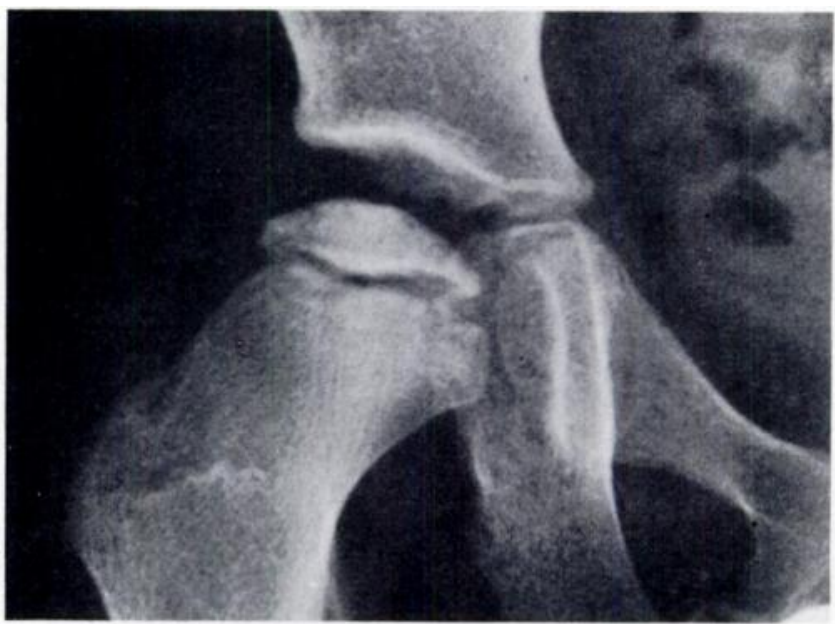

Fig. 10

Radiographs of a boy born in November 1968 who presented with Perthes' disease of the left hip in February 1972. Figure 7-June 1972, a dimple defect is apparent on the dome of the right femoral capital epiphysis. Figure 8-February 1974, the dimple has persisted although it is now more shallow. Figure 9-June 1974, the shallow dimple is still present and a second dimple is present in the lateral one-third of the contour of the dome. Figure 10-November 1974, two months after the first complaint of pain in his right leg, major capital collapse with the radiographic appearances of Perthes' disease of the right hip.

this might well interfere adversely with the speed of healing of such naturally occurring stress lesions.

Significance of the irregularities. Katz (1965) and Emr and Komprda (1968) have considered the possibility of these lesions being an abortive form of Perthes' disease. Whereas in the majority of instances the changes may seem to have little clinical significance, we have seen a number of children in whom a contour irregularity was the forerunner of classical Perthes' disease. Five of the children rejected from this study because they had bilateral Perthes' disease had only one hip involved initially and had contour defects in the normal hip which subsequently evolved to a full Perthes' lesion. Figures 7 to 10 show this evolution in a child not included in this study. In other children these surface irregularities have been associated with pain in the hip and with muscle spasm but have not progressed to a classic and full Perthes' disease.

The changes described in this paper are consistent with an hypothesis that we have advanced elsewhere (Burwell et al. 1978) that the femoral capital epiphysis in the young child may be vulnerable to stress; contour irregularities may be one end of the spectrum of the resultant effects, frank Perthes' disease the other.

We are grateful to the Arthritis and Rheumatism Council for a grant to M.E.B.; to the staff of the X-ray Departments of the Royal Orthopaedic Hospital, the Children's Hospital and the Accident Hospital, Birmingham, and the Gulson Road Hospital, Coventry; to Dr Clifford Astley, of the Birmingham Children's Hospital, for help in the formulation and study of control Series 1; to Mrs R. Bahia for providing invaluable secretarial and administrative assistance; and to Mr R. Gill for the photography. 


\section{REFERENCES}

Burwell RG, Dangerfield PH, Hall DJ, Vernon CL, Harrison MHM. Perthes' disease: an anthropometric study revealing impaired and disproportionate growth. J Bone Joint Surg [Br] 1978;60-B:461-77.

Catterall A. Natural history of Perthes' disease. British Orthopaedic Association Slide-Tape 73-13. Chelmsford: Graves Medical Audiovisual Library, 1973.

Catterall A, Lloyd-Roberts GC, Wynne-Davies R. Association of Perthes' disease with congenital anomalies of genitourinary tract and inguinal region. Lancet 1971;1:996-7.

Chivabongs A. Verlauft die Perthes'sche erkrankung vorwiegend einseitig? Z Orthop 1972;110:418-25.

Emr J, Komprda J. Developmental variation in epiphyseogenesis of the femoral head on the unaffected hip in unilateral Perthes' disease. S $b$ Ved Pr Lek Fak Karlovy Univ 1968;11:237-44.

Gorf CW. Legg-Calvé-Perthes syndrome and related osteochondroses of youth. Springfield, Illinois: Charles C Thomas, $1954: 41$.

Harrison MHM, Schajowicz F, Trueta J. Osteoarthritis of the hip: a study of the nature and evolution of the disease. J Bone Joint Surg [Br] 1953;35-B:598-626.

Harrison MHM, Turner MH, Jacobs P. Skeletal immaturity in Perthes' disease. J Bone Joint Surg [Br] 1976;58-B:37-40.

Katz JF. "Abortive" Legg-Calvé-Perthes disease or developmental variation in epiphyseogenesis of the upper femur J Mt Sinai Hosp NY 1965;32:651-9.

Katz JF. Minimal Legg-Calvé-Perthes disease. J Mt Sinai Hosp. NY 1968;35:408-16.

Kemp HS, Boldero JL. Radiological changes in Perthes' disease. Br J Radiol 1966;39:744-60.

Meyer J. Dysplasia epiphysealis capitis femoris. Acta Orthop Scand 1964;34:183-97.

Mose K. Legg-Calvé-Perthes disease. Universitetsforlaget I Aarhus, 1964.

Pedersen EK. Dysplasia epiphysialis capitis femoris. J Bone Joint Surg [Br] 1960;42-B:663.

Sundt H. Malum coxae Calvé-Legg-Perthes'. Acta Chir Scand 1949;Supplement 148.

Wynne-Davies R, Gormley J. The aetiology of Perthes' disease. J Bone Joint Surg [Br] 1978;60-B:6-14. 